\title{
BMJ open Weekend admissions as an independent predictor of mortality: an analysis of Scottish hospital admissions
}

\author{
Adam E Handel, ${ }^{1,2}$ Sunil V Patel, ${ }^{3,4}$ Andrew Skingsley, ${ }^{3,5}$ Katrina Bramley, ${ }^{3,6}$ \\ Roma Sobieski, ${ }^{3}$ Sreeram V Ramagopalan ${ }^{1,2,3,7}$
}

To cite: Handel AE, Patel SV, Skingsley A, et al. Weekend admissions as an independent predictor of mortality: an analysis of Scottish hospital admissions. BMJ Open 2012;2:e001789. doi:10.1136/bmjopen-2012001789

- Prepublication history and additional material for this paper are available online. To view these files please visit the journal online (http://dx.doi.org/10.1136/ bmjopen-2012-001789).

Received 11 July 2012 Accepted 4 October 2012

This final article is available for use under the terms of the Creative Commons Attribution Non-Commercial 2.0 Licence; see http://bmjopen.bmj.com

For numbered affiliations see end of article

\section{Correspondence to} Dr Sunil V Patel; Sunil.Patel@londonhospitals. ca,

Dr Sreeram V Ramagopalan; s.ramagopalan@qmul.ac.uk

\section{ABSTRACT}

Objectives: Weekend admissions have been shown to be associated with an increased risk of mortality compared with weekday admissions for many diagnoses. We analysed emergency department admissions within the Scottish National Health Service to investigate whether mortality is increased in case of weekend emergency department admissions.

Design: A cohort study.

Setting: Scotland National Health Service (NHS) emergency departments.

Participants: 5271327 emergency department admissions between 1999 and 2009. We included all patients admitted via emergency departments recorded in the Scottish Morbidity Records (SMR01) in NHS, Scotland for whom complete demographic data were available.

Primary outcome measures: Death as recorded by the General Register Office (GR0).

Results: There was a significantly increased probability of death associated with a weekend emergency admission compared with admission on a weekday (unadjusted OR 1.27, 95\% Cl 1.26 to 1.28 , $p<0.0001$; adjusted for year of admission, gender, age, deprivation quintile and number of comorbidities $\mathrm{OR}$ $1.42,95 \%$ Cl 1.40 to $1.43, p<0.0001)$.

Conclusions: Despite a general reduction in mortality over the last 11 years, there is still a significant excess mortality associated with weekend emergency admissions. Further research should be undertaken to identify the precise mechanisms underlying this effect so that measures can be put in place to reduce patient mortality.

\section{INTRODUCTION}

Service provision within National Health Service (NHS) hospitals has traditionally been organised around a fundamental division between weekdays and weekends. However, mortality data drawn from many different sources indicate that weekend admission to hospital is associated with an increased risk of death. ${ }^{1-5}$ This has prompted a shift in health policies within the UK

\section{ARTICLE SUMMARY}

Article focus

- Weekend admissions have been associated with excess mortality.

- This article addresses whether this excess mortality is seen in emergency admissions from National Health Service, Scotland between 1999 and 2009.

Key messages

- The risk of death associated with weekend emergency admissions is significantly higher than that of weekday emergency admissions.

- This risk persists even when adjusted for year of admission, gender, age, deprivation quintile and number of comorbidities.

Strengths and limitations of this study

- This study uses a large, nationally registered cohort of admissions obtained over a long time period.

- Although able to adjust for many confounding variables, it was not possible to adjust for the admitting diagnosis or severity of presenting a complaint.

towards consideration of a 7-day working week within the NHS.

The evidence illustrating an adverse effect of weekend admission on death rates is strong and growing constantly. A recent study using the NHS database of all NHS hospital admissions within England showed a significantly increased risk of death for patients admitted at the weekend, even when adjusted for multiple potential confounders. ${ }^{5}$ Similar analyses of emergency admissions within multiple hospitals in England and Spain have shown a similar detrimental effect of weekend admissions on survival. ${ }^{3} 4$ Increased mortality with weekend admissions is consistent across multiple pathologies suggesting a systematic failure of care. ${ }^{6-9}$ One study from Canada suggested an increased rate of mortality for some causes of admission 
(ruptured aortic aneurysm, pulmonary embolism and acute epiglottitis) but not others (acute myocardial infarction, hip fracture and intracranial haemorrhage), ${ }^{1}$ although subsequent studies from the USA suggest that myocardial infarction presenting at weekends is associated with an increased mortality. ${ }^{6}$ A similar effect was observed for acute kidney injury and stroke. ${ }^{89}$

This effect spans multiple different age groups (perinatal mortality is increased at weekends, although not when adjusted for birth weight) and clinical areas (intensive care admissions at the weekend are associated with an increased mortality) ${ }^{10-12}$ Particularly influential to policies has been the report by Dr Foster on an increased hospital mortality in the UK at weekends, which has been linked to a reduced cover by senior doctors at weekends. ${ }^{13} 14$

In this study, we aimed to investigate emergency admissions within NHS, Scotland to establish if a similar effect of weekend admissions on mortality occurred in this region.

\section{METHODS}

Scottish admissions data

The Scottish Morbidity Records (SMR01) database of Scottish inpatient/daycase admissions and General Register Office (GRO) death records for Scotland were accessed on 26 February 2011 for emergency department admissions. The basic unit of analysis was the continuous spell of treatment (CIS). These were grouped according to the admission date, gender, age, deprivation quintile (based on Scottish Index of Multiple Deprivation 2009 V.2 Scotland level population-weighted quintile, where 1 is the most deprived and 5 , the least) and number of recorded comorbidities. Probability matching methods were used to link together separate SMR01 hospital episodes for each patient, thereby creating 'linked' patient histories. Within these patient histories, SMR01 episodes are grouped according to whether they form part of a continuous spell of treatment (whether or not this involves transfer between hospitals or even Health Boards). Mortality during admission was derived from the GRO death record linked to the SMR.

\section{Ethics statement}

Anonymised data were used and we therefore followed the ethical principles of existing UK data protection legislation and guidance, including two National Statistics Protocols on data access and confidentiality, and data matching. Thus specific ethical approval was not required for this study according to the guidelines at http://www.nhsnss.org/pages/corporate/privacy_advisory_ committee.php, which permitted the release of the data used in this study.

\section{Statistical analysis}

Data were analysed in STATA V.12.0 (StataCorp LP, College Station, Texas, USA). Multiple logistic regression was used for calculating ORs, 95\% CIs and $p$ values for individual factors. We interpreted $\mathrm{p}$ values of $<0.05$ as nominally significant. $\chi^{2}$ Tests were used for testing for significance of trends within factors. Only records without missing data were included in the multiple logistic regression model.

\section{RESULTS}

Scottish emergency department admissions

There were 5343906 admissions to emergency departments in Scotland between 1999 and 2009, of which $5271327(98.6 \%)$ had admission date, gender, age, deprivation quintile and number of comorbidities recorded. Of all admissions, $270463(5.03 \%)$ ended in death. This was very similar to the proportion of admissions for which all data were recorded that ended in death $(266119(5.05 \%))$. The majority of deaths for which all data were recorded occurred during weekdays (191 929, 4.77\% of weekday admissions) rather than on weekends ( $74190,5.77 \%$ of weekend admissions). The subsequent analysis applies only to those admissions with complete records of the above data. About $4025845(76.4 \%)$ of these were on weekdays and $1245482(23.6 \%)$ on weekends. There were few admissions during weekends than expected from a random distribution $(23.6 \%$ observed vs $28.6 \%$ expected, $\mathrm{p}<0.0001)$. Admissions and death rates broken down by each category are shown in table 1 .

\section{Mortality for weekend admissions compared with weekday} admissions

The mortality for weekend admissions was found to be higher than that for weekday admissions $(5.96 \%$ vs $4.77 \%$, unadjusted OR $1.27,95 \%$ CI 1.26 to 1.28 , $\mathrm{p}<0.0001)$. The effect of weekend admissions was still statistically significant when adjusted for admission year, gender, age group, deprivation quintile and number of comorbidities (adjusted OR 1.42, 95\% CI 1.40 to 1.43 , $\mathrm{p}<0.0001$ ). All of the potential confounders included in the logistic regression model were independently statistically associated with the probability of death for emergency admissions as shown in tables 1 and 2. Notably, the number of comorbidities shows an inverse trend on mortality that would not be expected a priori. Further, mortality after being admitted to a hospital has been declining over time (2009 mortality was $25 \%$ less than that in 1999, $\mathrm{p}<0.0001)$. However, the effect of admission at weekends on mortality remained much the same throughout the 11-year period studied (table 3).

\section{Causes of death}

Our study was not designed to investigate cause-specific aspects of mortality data. Table 4 shows the top 50 causes of death for weekend and weekday admissions. The patterns of mortality seem to appear relatively similar between weekends and weekdays. Further research would be needed to gather diagnosis-specific admission data to analyse mortality further. 
Table 1 Number and percentages of emergency department admissions by category

\begin{tabular}{|c|c|c|c|c|c|c|c|c|c|}
\hline & \multirow[b]{2}{*}{ Weekdays } & \multirow[b]{2}{*}{ Weekends } & \multirow[b]{2}{*}{ Total } & \multirow[b]{2}{*}{ Mortality (\%) } & \multirow[b]{2}{*}{ OR } & \multicolumn{2}{|l|}{$95 \% \mathrm{Cl}$} & \multirow[b]{2}{*}{ p Values } & \multirow[b]{2}{*}{ Test for trend } \\
\hline & & & & & & Lower limit & Upper limit & & \\
\hline Weekdays & & & 4025845 & 4.77 & 1 & & & $<0.0001$ & $\mathrm{~N} / \mathrm{A}$ \\
\hline Weekends & & & 1245482 & 5.96 & 1.27 & 1.26 & 1.28 & & \\
\hline \multicolumn{10}{|l|}{ Gender } \\
\hline Male & 1970465 & 638824 & 2609289 & 4.81 & 1 & & & $<0.0001$ & $\mathrm{~N} / \mathrm{A}$ \\
\hline Female & 2055380 & 606658 & 2662038 & 5.28 & 1.10 & 1.09 & 1.11 & & \\
\hline \multicolumn{10}{|c|}{ Socioeconomic status (quintile) } \\
\hline 1 & 1155112 & 371259 & 1526371 & 4.50 & 1 & & & $<0.0001$ & $<0.0001$ \\
\hline 2 & 936322 & 291406 & 1227728 & 5.22 & 1.17 & 1.16 & 1.18 & & \\
\hline 3 & 765169 & 232479 & 997648 & 5.34 & 1.20 & 1.18 & 1.21 & & \\
\hline 4 & 638357 & 192826 & 831183 & 5.37 & 1.20 & 1.19 & 1.22 & & \\
\hline 5 & 530885 & 157512 & 688397 & 5.15 & 1.15 & 1.14 & 1.17 & & \\
\hline \multicolumn{10}{|c|}{ Number of comorbidities } \\
\hline None & 1124395 & 319905 & 1444300 & 3.92 & 1 & & & $<0.0001$ & $<0.0001$ \\
\hline 1 & 1007851 & 327562 & 1335413 & 5.81 & 1.51 & 1.49 & 1.53 & & \\
\hline 2 & 673034 & 219715 & 892749 & 7.79 & 2.07 & 2.05 & 2.09 & & \\
\hline 3 & 463688 & 149129 & 612817 & 6.42 & 1.68 & 1.66 & 1.70 & & \\
\hline 4 & 307090 & 95809 & 402899 & 4.20 & 1.07 & 1.05 & 1.09 & & \\
\hline 5 or more & 449787 & 133362 & 583149 & 1.05 & 0.26 & 0.25 & 0.27 & & \\
\hline \multicolumn{10}{|l|}{ Year } \\
\hline 1999 & 347449 & 106811 & 454260 & 5.61 & 1 & & & $<0.0001$ & $<0.0001$ \\
\hline 2000 & 344877 & 110367 & 455244 & 5.30 & 0.94 & 0.92 & 0.96 & & \\
\hline 2001 & 356045 & 111299 & 467344 & 5.24 & 0.93 & 0.91 & 0.95 & & \\
\hline 2002 & 353933 & 111143 & 465076 & 5.33 & 0.95 & 0.93 & 0.96 & & \\
\hline 2003 & 351200 & 109541 & 460741 & 5.41 & 0.96 & 0.95 & 0.98 & & \\
\hline 2004 & 357885 & 109013 & 466898 & 5.10 & 0.90 & 0.89 & 0.92 & & \\
\hline 2005 & 359495 & 109439 & 468934 & 5.17 & 0.92 & 0.90 & 0.93 & & \\
\hline 2006 & 374469 & 115083 & 489552 & 4.88 & 0.86 & 0.85 & 0.88 & & \\
\hline 2007 & 389490 & 118794 & 508284 & 4.71 & 0.83 & 0.82 & 0.85 & & \\
\hline 2008 & 399693 & 122287 & 521980 & 4.70 & 0.83 & 0.81 & 0.84 & & \\
\hline 2009 & 391309 & 121705 & 513014 & 4.28 & 0.75 & 0.74 & 0.77 & & \\
\hline \multicolumn{10}{|c|}{ Age group (years) } \\
\hline$<5$ & 261494 & 88143 & 349637 & 0.11 & 0.07 & 0.06 & 0.08 & $<0.0001$ & $<0.0001$ \\
\hline $5-9$ & 92314 & 31431 & 123745 & 0.09 & 0.05 & 0.04 & 0.06 & & \\
\hline $10-14$ & 98947 & 32368 & 131315 & 0.10 & 0.06 & 0.05 & 0.07 & & \\
\hline $15-19$ & 130618 & 57024 & 187642 & 0.19 & 0.12 & 0.11 & 0.13 & & \\
\hline $20-24$ & 146214 & 59527 & 205741 & 0.21 & 0.13 & 0.11 & 0.14 & & \\
\hline $25-29$ & 144387 & 53194 & 197581 & 0.26 & 0.16 & 0.14 & 0.17 & & \\
\hline $30-34$ & 162363 & 55380 & 217743 & 0.40 & 0.25 & 0.23 & 0.26 & & \\
\hline $35-39$ & 188940 & 62452 & 251392 & 0.65 & 0.40 & 0.38 & 0.42 & & \\
\hline $40-44$ & 203361 & 64776 & 268137 & 1.03 & 0.63 & 0.60 & 0.66 & & \\
\hline $45-49^{*}$ & 207744 & 63986 & 271730 & 1.62 & 1 & & & & \\
\hline $50-54$ & 220087 & 65356 & 285443 & 2.48 & 1.54 & 1.48 & 1.60 & & \\
\hline $55-59$ & 237037 & 68203 & 305240 & 3.50 & 2.20 & 2.12 & 2.28 & & \\
\hline $60-64$ & 267869 & 75438 & 343307 & 4.85 & 3.09 & 2.98 & 3.19 & & \\
\hline 65-69 & 298468 & 83581 & 382049 & 6.33 & 4.09 & 3.96 & 4.23 & & \\
\hline $70-74$ & 339743 & 93689 & 433432 & 8.00 & 5.27 & 5.10 & 5.44 & & \\
\hline $75-79$ & 359849 & 100280 & 460129 & 9.91 & 6.67 & 6.46 & 6.88 & & \\
\hline $80-84$ & 318555 & 90036 & 408591 & 11.85 & 8.15 & 7.89 & 8.41 & & \\
\hline$\geq 85$ & 347855 & 100618 & 448473 & 14.98 & 10.67 & 10.34 & 11.02 & & \\
\hline
\end{tabular}

The number and percentage of emergency department admissions for each category are shown in the above table, along with the percentage that ended in death. The unadjusted OR along with lower and upper limits of the $95 \%$ Cls are shown in each row along with the significance for the test and significance for the trend within each category, if appropriate. Note that this analysis includes only those admissions where complete records of all potential confounders were kept.

*Patients under the age group 45-49 were used as the baseline group for calculation of ORs. 
Table 2 Results of a logistic regression analysis of emergency department admissions and mortality

\begin{tabular}{|c|c|c|c|c|}
\hline & \multirow[b]{2}{*}{ OR } & \multicolumn{2}{|l|}{$95 \% \mathrm{Cl}$} & \multirow[b]{2}{*}{ p Values } \\
\hline & & Lower limit & Upper limit & \\
\hline Weekdays & 1 & & & \\
\hline Weekends & 1.42 & 1.40 & 1.43 & $<0.0001$ \\
\hline \multicolumn{5}{|l|}{ Year } \\
\hline 1999 & 1.00 & & & \\
\hline 2000 & 0.94 & 0.93 & 0.96 & $<0.0001$ \\
\hline 2001 & 0.95 & 0.93 & 0.97 & \\
\hline 2002 & 1.00 & 0.98 & 1.02 & \\
\hline 2003 & 1.03 & 1.02 & 1.05 & \\
\hline 2004 & 1.02 & 1.00 & 1.04 & \\
\hline 2005 & 1.05 & 1.03 & 1.07 & \\
\hline 2006 & 0.97 & 0.96 & 0.99 & \\
\hline 2007 & 0.91 & 0.90 & 0.93 & \\
\hline 2008 & 0.89 & 0.87 & 0.91 & \\
\hline 2009 & 0.81 & 0.80 & 0.83 & \\
\hline \multicolumn{5}{|c|}{ Age group (years) } \\
\hline$<5$ & 0.06 & 0.06 & 0.07 & \\
\hline $5-9$ & 0.05 & 0.04 & 0.06 & $<0.0001$ \\
\hline $10-14$ & 0.05 & 0.05 & 0.07 & \\
\hline $15-19$ & 0.11 & 0.10 & 0.12 & \\
\hline 20-24 & 0.12 & 0.11 & 0.13 & \\
\hline $25-29$ & 0.15 & 0.14 & 0.16 & \\
\hline 30-34 & 0.24 & 0.22 & 0.25 & \\
\hline 35-39 & 0.39 & 0.37 & 0.41 & \\
\hline $40-44$ & 0.62 & 0.59 & 0.65 & \\
\hline $45-49^{*}$ & 1 & & & \\
\hline $50-54$ & 1.56 & 1.50 & 1.62 & \\
\hline $55-59$ & 2.28 & 2.20 & 2.36 & \\
\hline $60-64$ & 3.31 & 3.20 & 3.42 & \\
\hline $65-69$ & 4.54 & 4.39 & 4.69 & \\
\hline $70-74$ & 6.08 & 5.89 & 6.28 & \\
\hline $75-79$ & 8.00 & 7.75 & 8.26 & \\
\hline $80-84$ & 10.19 & 9.88 & 10.52 & \\
\hline$\geq 85$ & 13.77 & 13.35 & 14.20 & \\
\hline \multicolumn{5}{|l|}{ Gender } \\
\hline Male & 1 & & & \\
\hline Female & 0.85 & 0.84 & 0.85 & $<0.0001$ \\
\hline \multicolumn{5}{|c|}{ Socioeconomic status (quintile) } \\
\hline 1 & 1 & & & \\
\hline 2 & 1.00 & 0.99 & 1.01 & $<0.0001$ \\
\hline 3 & 0.98 & 0.97 & 0.99 & \\
\hline 4 & 0.97 & 0.96 & 0.99 & \\
\hline 5 & 0.93 & 0.92 & 0.95 & \\
\hline \multicolumn{5}{|c|}{ Number of comorbidities } \\
\hline None & 1 & & & \\
\hline 1 & 1.24 & 1.23 & 1.26 & $<0.0001$ \\
\hline 2 & 1.34 & 1.32 & 1.35 & \\
\hline 3 & 0.90 & 0.89 & 0.91 & \\
\hline 4 & 0.50 & 0.49 & 0.51 & \\
\hline 5 or more & 0.11 & 0.10 & 0.11 & \\
\hline
\end{tabular}

The adjusted OR along with lower and upper limits of the 95\% Cls are shown in each row along with the significance for the test and significance for the trend within each category, if appropriate. These were derived from a logistic regression analysis. Note that this analysis includes only those admissions where complete records of all potential confounders were kept.

*Patients under theage group of $45-49$ were used as the baseline group for the calculation of OR
Table 3 Odds of mortality of those admitted during weekends, compared with those admitted during weekdays, stratified by year

\begin{tabular}{lllll}
\hline & & \multicolumn{2}{l}{$\mathbf{9 5 \%}$ Cl } & \\
Year & OR & Lower limit & Upper limit & p Values \\
\hline 1999 & 1.46 & 1.41 & 1.50 & $<0.001$ \\
2000 & 1.38 & 1.34 & 1.42 & $<0.001$ \\
2001 & 1.38 & 1.34 & 1.43 & $<0.001$ \\
2002 & 1.44 & 1.40 & 1.49 & $<0.001$ \\
2003 & 1.42 & 1.38 & 1.46 & $<0.001$ \\
2004 & 1.47 & 1.42 & 1.51 & $<0.001$ \\
2005 & 1.44 & 1.39 & 1.48 & $<0.001$ \\
2006 & 1.40 & 1.36 & 1.45 & $<0.001$ \\
2007 & 1.44 & 1.39 & 1.48 & $<0.001$ \\
2008 & 1.40 & 1.36 & 1.44 & $<0.001$ \\
2009 & 1.35 & 1.31 & 1.40 & $<0.001$ \\
\hline
\end{tabular}

\section{DISCUSSION}

Our study shows that the excess of admissions ending in deaths at weekends compared with those during weekdavs seen elsewhere were also found in Scotland and, in fact, appear to be of a larger magnitude than the effects reported elsewhere (table 5). Despite a reduction in mortality over the course of the study, after adjusting for this and multiple other potential confounding variables, the weekend effect on mortality remains.

The strength of our study is that it analyses data from a large number of emergency admissions drawn from over a relatively long period of 11 years. There are a number of limitations. We lack data on cause and severity of admissions. The analysis relies on the accuracy of data input by clinicians and clerical staff involved in individual admissions and thus unlikely to be entirely accurate. Furthermore, since the regression analysis only included records with complete data recorded, there is a possibility of introducing systematic bias into our study.

Several possible explanations may clarify the seemingly counter-intuitive finding that the number of comorbidities is inversely associated with mortality. It is possible that timing of utilisation of emergency department admissions differs by number of comorbidities or that this merely reflects a survivor effect, whereby those that live longer accumulate more comorbid diagnoses.

The cause for this increased mortality is an area of considerable debate. Many of the studies reporting excess deaths at weekends adjusted for many of the obvious potential confounders (age, comorbidities, deprivation, etc). However, interestingly the effect appears to be persistent even when more careful analyses adjusting for specific confounders that would a priori be hypothesised to be adversely affected at weekends, such as time to angiography for myocardial infarction and time to oesophagogastroduodenoscopy in peptic ulcer-related upper gastrointestinal haemorrhage. ${ }^{6715}$ However, in a recent study from Australia it was noted that, of the conditions they assessed (myocardial infarction, chronic obstructive 


\section{Rank Weekends}

Malignant neoplasm of bronchus and lung

Chronic ischaemic heart disease

Acute myocardial infarction

Other septicaemia

Pneumonia, organism unspecified

Other chronic obstructive pulmonary

disease

7 Stroke, not specified as haemorrhage or infarction

Malignant neoplasm of breast

Heart failure

10 Malignant neoplasm of colon

11 Malignant neoplasm without specification of site

12 Malignant neoplasm of prostate

13 Malignant neoplasm of oesophagus

14 Non-insulin-dependent diabetes mellitus

15 Unspecified diabetes mellitus

16 Alcoholic liver disease

17 Malignant neoplasm of pancreas

18 Atrial fibrillation and flutter

19 Intracerebral haemorrhage

20 Malignant neoplasm of stomach

Cerebral infarction

Malignant neoplasm of bladder

Unspecified dementia

Essential (primary) hypertension

Malignant neoplasm of ovary

Other cerebrovascular diseases

Pulmonary embolism

Pneumonitis due to solids and liquids

Other and unspecified types of

non-Hodgkin's lymphoma

30 Sequelae of cerebrovascular disease $\quad 465 \quad 23.13$

31 Aortic aneurysm and dissection $489 \quad 24.39$

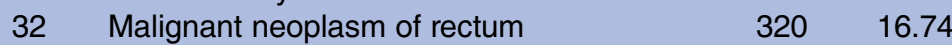

33 Malignant neoplasm of kidney, except renal $280 \quad 15.23$

pelvis

34 Malignant neoplasm of liver and intrahepatic 307 bile ducts

$4406 \quad 24.39$

$3656 \quad 22.16$

$2368 \quad 26.71$

$1058 \quad 16.80$

$1226 \quad 22.12$

$946 \quad 18.06$

16.37

17.93

17.75

20.85

22.41

19.01

17.43

24.02

25.77

16.77

27.01

17.33

23.69

23.23

17.81

22.20

21.07

24.37

17.43
Number Percentage Weekdays

Combined deaths

(weekends

Number Percentage and weekdays)

$\begin{array}{llllll}4281 & 18.87 & \text { Malignant neoplasm of bronchus and lung } & 18400 & 81.13 & 22681\end{array}$

$3029-23.00$

hus and lung

$14536 \quad 78.18$

Acute myocardial infarction $\quad 13658 \quad 75.61$

$12839 \quad 77.84$

Pneumonia, organism unspecified

Other chronic obstructive pulmonary

disease

Stroke, not specified as haemorrhage or

$10139 \quad 77.00$

$6708 \quad 75.51$

infarction

Malignant neoplasm of breast

Heart failure

Malignant neoplasm of colon

Malignant neoplasm without specification of site

Malignant neoplasm of prostate

Malignant neoplasm of oesophagus

Non-insulin-dependent diabetes mellitus

Unspecified diabetes mellitus

Alcoholic liver disease

Malignant neoplasm of pancreas

Atrial fibrillation and flutter

Intracerebral haemorrhage

Malignant neoplasm of stomach

Cerebral infarction

Malignant neoplasm of bladder

Unspecified dementia

Essential (primary) hypertension

Malignant neoplasm of ovary

Other cerebrovascular diseases

Pulmonary embolism

Pneumonitis due to solids and liquids

Other and unspecified types of

non-Hodgkin's Iymphoma

Sequelae of cerebrovascular disease

Aortic aneurysm and dissection

Malignant neoplasm of rectum

Malignant neoplasm of kidney, except renal pelvis

Malignant neoplasm of liver and intrahepatic bile ducts 
Table 4 Continued

\begin{tabular}{|c|c|c|c|c|c|c|c|}
\hline Rank & Weekends & Number & Percentage & Weekdays & Number & Percentage & $\begin{array}{l}\text { Combined deaths } \\
\text { (weekends } \\
\text { and weekdays) }\end{array}$ \\
\hline 35 & Malignant neoplasm of brain & 271 & 17.18 & Malignant neoplasm of brain & 1306 & 82.82 & 1577 \\
\hline 36 & $\begin{array}{l}\text { Multiple myeloma and malignant plasma cell } \\
\text { neoplasms }\end{array}$ & 265 & 17.64 & $\begin{array}{l}\text { Multiple myeloma and malignant plasma cell } \\
\text { neoplasms }\end{array}$ & 1237 & 82.36 & 1502 \\
\hline 37 & $\begin{array}{l}\text { Malignant neoplasm of rectosigmoid } \\
\text { junction }\end{array}$ & 222 & 14.90 & $\begin{array}{l}\text { Malignant neoplasm of rectosigmoid } \\
\text { junction }\end{array}$ & 1268 & 85.10 & 1490 \\
\hline 38 & Myeloid leukaemia & 247 & 17.13 & Myeloid leukaemia & 1195 & 82.87 & 1442 \\
\hline 39 & Unspecified fall & 377 & 26.44 & Unspecified fall & 1049 & 73.56 & 1426 \\
\hline 40 & Non-rheumatic aortic valve disorders & 244 & 17.55 & Nonrheumatic aortic valve disorders & 1146 & 82.45 & 1390 \\
\hline 41 & $\begin{array}{l}\text { Malignant neoplasm of other and ill-defined } \\
\text { digestive organs }\end{array}$ & 233 & 17.65 & $\begin{array}{l}\text { Malignant neoplasm of other and ill-defined } \\
\text { digestive organs }\end{array}$ & 1087 & 82.35 & 1320 \\
\hline 42 & Other disorders of urinary system & 317 & 24.11 & Other disorders of urinary system & 998 & 75.89 & 1315 \\
\hline 43 & Vascular dementia & 252 & 19.58 & Vascular dementia & 1035 & 80.42 & 1287 \\
\hline 44 & Subarachnoid haemorrhage & 332 & 28.23 & Subarachnoid haemorrhage & 844 & 71.77 & 1176 \\
\hline 45 & Other peripheral vascular diseases & 226 & 19.28 & Other peripheral vascular diseases & 946 & 80.72 & 1172 \\
\hline 46 & Other bacterial intestinal infections & 280 & 24.93 & Other bacterial intestinal infections & 843 & 75.07 & 1123 \\
\hline 47 & Parkinson's disease & 194 & 18.28 & Parkinson's disease & 867 & 81.72 & 1061 \\
\hline 48 & Unspecified acute lower respiratory infection & 259 & 25.77 & Unspecified acute lower respiratory infection & 746 & 74.23 & 1005 \\
\hline 49 & $\begin{array}{l}\text { Mental and behavioural disorders due to } \\
\text { use of alcohol }\end{array}$ & 259 & 25.87 & $\begin{array}{l}\text { Mental and behavioural disorders due to } \\
\text { use of alcohol }\end{array}$ & 742 & 74.13 & 1001 \\
\hline 50 & Other interstitial pulmonary diseases & 216 & 23.20 & Other interstitial pulmonary diseases & 715 & 76.80 & 931 \\
\hline
\end{tabular}

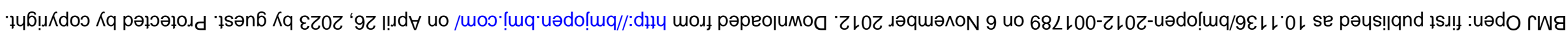


Table 5 Previous studies of emergency admissions and mortality for weekdays and weekends admissions

\begin{tabular}{|c|c|c|c|c|c|}
\hline \multirow{2}{*}{$\begin{array}{l}\text { Study } \\
\text { First author }\end{array}$} & \multirow[b]{2}{*}{ Year } & \multirow[t]{2}{*}{ OR } & \multicolumn{2}{|c|}{$95 \% \mathrm{Cl}$} & \multirow[b]{2}{*}{ Notes } \\
\hline & & & Lower & Upper & \\
\hline Barba & 2006 & 1.40 & 1.18 & 1.62 & $\begin{array}{l}\text { Single centre study in Spain 1999-2003 excluding all elective } \\
\text { admissions, elective transfers, critical care patients and births. Adjusted } \\
\text { for age, gender, diagnosis-related group weight and comorbidity. }\end{array}$ \\
\hline Aylin & 2010 & 1.10 & 1.08 & 1.11 & $\begin{array}{l}\text { National Health Service (NHS), England emergency admissions } \\
\text { 2005/2006. Adjusted for age, sex, deprivation quintile and comorbidity. }\end{array}$ \\
\hline Marco & 2010 & 1.07 & 1.05 & 1.10 & $\begin{array}{l}\text { Spanish NHS emergency admissions to internal medicine wards } 2005 . \\
\text { Adjusted for age, sex and comorbidity }\end{array}$ \\
\hline \multirow[t]{2}{*}{ Freemantle } & $\begin{array}{l}2012 \\
\text { (Sat vs Wed) }\end{array}$ & 1.11 & 1.09 & 1.13 & $\begin{array}{l}\text { NHS, England emergency admissions } 2009 / 2010 \text {. Adjusted for age; sex; } \\
\text { ethnicity; whether the admission was classified as an emergency; source } \\
\text { of admission (eg, from home or transfer from another hospital); } \\
\text { diagnostic group; number of previous emergency admissions; number of } \\
\text { previous complex admissions; comorbidity; social deprivation; hospital } \\
\text { trust; day of the year (seasonality) and the day of admission. }\end{array}$ \\
\hline & (Sun vs Wed) & 1.14 & 1.12 & 1.16 & $\begin{array}{l}\text { NHS, England emergency admissions } 2009 / 2010 \text {. Adjusted for age; sex; } \\
\text { ethnicity; whether the admission was classified as an emergency; source } \\
\text { of admission (eg, from home or transfer from another hospital); } \\
\text { diagnostic group; number of previous emergency admissions; number of } \\
\text { previous complex admissions; comorbidity; social deprivation; hospital } \\
\text { trust; day of the year (seasonality); and the day of admission. }\end{array}$ \\
\hline
\end{tabular}

pulmonary disease, intracranial haemorrhage and acute hip fracture), there was observed an association of weekend admissions with mortality in myocardial infarction, the condition in which a delay to instrumentation is likely to have the largest effect on outcome. ${ }^{16}$ Certainly, institutional standards appear to be able to mitigate the excess weekend mortality, at least in case of ischaemic strokes, wherein no increase in mortality for weekend admissions has been observed in 'comprehensive stroke centres' within the USA, but is still seen in less-specialist centres. ${ }^{9}$ It may also be that emergency departments see a different, more unwell population of patients at weekends, since, in one study which used a biochemical measure of severity, adjustment for this variable rendered the weekend effect insignificant. ${ }^{17}$ It is possible that a confounding variable associated with severity, for which we were unable to control, underlies the weekend effect. This could mean that the effect we observe is actually due to admissions over the weekend comprising a more unwell population of patients, who would suffer a higher rate of mortality regardless of factors that may apply exclusively to the weekend.

It is clearly critical to understand the precise cause of this excess mortality before measures can be put in place to mitigate the effect of weekend admissions on survival, particularly given the potentially huge costs involved in upgrading weekend services. Resources and manpower in the hospital will clearly play a huge part in this, however, the importance of reduced primary care support at weekends in the community should not be forgotten, since early identification of unwell patients is likely to improve later outcomes and out-of-hours primary care has been shown to alter the profile of emergency department admissions. ${ }^{18} 19$ Further work should focus on understanding the precise mechanism behind the increased mortality observed for weekend admissions so that effective measures can be implemented to combat this. Ideally, this would entail ascertaining diagnosis and severity-specific weekend mortality by region and level of service infrastructure, incorporating broad aspects of prebased care and hospital-based care.

\section{Author affiliations}

${ }^{1}$ Wellcome Trust Centre for Human Genetics, University of Oxford, Oxford, UK

${ }^{2}$ Nuffield Department of Clinical Neurosciences (Clinical Neurology), University of Oxford, Oxford, UK

${ }^{3}$ Department of Epidemiology, London School of Hygiene and Tropical Medicine, London, UK

${ }^{4}$ Department of Surgery, London Health Sciences Centre, London, Canada ${ }^{5}$ Department of Epidemiology and Public Health, Imperial College Medical School. London, UK

${ }^{6}$ Department of Anaesthesia, Glasgow Royal Infirmary, Glasgow, UK ${ }^{7}$ Blizard Institute, Queen Mary University of London, Barts and The London School of Medicine and Dentistry, London, UK

Acknowledgements We are grateful to NHS, Scotland for providing us with data and to colleagues for many useful and informative conversations.

Contributors AEH and SVR conceived the study idea. SVP analysed the data. $A E H, S V P, A S, K B, R S$ and SVR wrote the paper.

Funding This work was funded by the Wellcome Trust (Grant Number $075491 / Z / 04)$. The funder had no role in data analysis or deciding to submit this manuscript for publication.

Competing interests None.

Provenance and peer review Not commissioned; externally peer-reviewed.

Data sharing statement Extra data can be accessed via the Dryad data repository at http://datadryad.org/with the D0I:10.5061/dryad.rm857. 


\section{REFERENCES}

1. Bell CM, Redelmeier DA. Mortality among patients admitted to hospitals on weekends as compared with weekdays. $N$ Engl J Med 2001;345:663-8.

2. Barba R, Losa JE, Velasco M, et al. Mortality among adult patients admitted to the hospital on weekends. Eur J Intern Med 2006;17:322-4.

3. Aylin P, Yunus A, Bottle A, et al. Weekend mortality for emergency admissions. A large, multicentre study. Qual Saf Health Care 2010;19:213-17.

4. Marco J, Barba R, Plaza S, et al. Analysis of the mortality of patients admitted to internal medicine wards over the weekend. Am J Med Qual 2010;25:312-18.

5. Freemantle N, Richardson M, Wood J, et al. Weekend hospitalization and additional risk of death: an analysis of inpatient data. J R Soc Med 2012;105:74-84.

6. Kostis WJ, Demissie K, Marcella SW, et al. Weekend versus weekday admission and mortality from myocardial infarction. $N$ Engl J Med 2007;356:1099-109.

7. Myers RP, Kaplan GG, Shaheen AM. The effect of weekend versus weekday admission on outcomes of esophageal variceal hemorrhage. Can J Gastroenterol 2009;23:495-501.

8. James MT, Wald R, Bell CM, et al. Weekend hospital admission, acute kidney injury, and mortality. J Am Soc Nephrol 2010;21:845-51.

9. McKinney JS, Deng Y, Kasner SE, et al. Comprehensive stroke centers overcome the weekend versus weekday gap in stroke treatment and mortality. Stroke 2011;42:2403-9.

10. Hamilton $\mathrm{P}$, Restrepo $\mathrm{E}$. Weekend birth and higher neonatal mortality: a problem of patient acuity or quality of care? J Obstet Gynecol Neonatal Nurs 2003;32:724-33.
11. Gould JB, Qin C, Marks AR, et al. Neonatal mortality in weekend vs weekday births. JAMA 2003;289:2958-62.

12. Barnett MJ, Kaboli PJ, Sirio CA, et al. Day of the week of intensive care admission and patient outcomes: a multisite regional evaluation. Med Care 2002;40:530-9.

13. Inside your hospital Dr Foster Hospital Guide 2001-2011.http:// drfosterintelligence.co.uk/wp-content/uploads/2011/11/ Hospital_Guide_2011.pdf (accessed 30 Mar 2012).

14. Goddard AF, Lees P. Higher senior staffing levels at weekends and reduced mortality. BMJ 2012;344:e67.

15. Shaheen AAM, Kaplan GG, Myers RP. Weekend versus weekday admission and mortality from gastrointestinal hemorrhage caused by peptic ulcer disease. Clin Gastroenterol Hepatol 2009;7:303-10

16. Clarke MS, Wills R-A, Bowman RV, et al. Exploratory study of the 'weekend effect' for acute medical admissions to public hospitals in Queensland, Australia. Intern Med J 2010;40:777-83.

17. Mikulich $\mathrm{O}$, Callaly $\mathrm{E}$, Bennett $\mathrm{K}$, et al. The increased mortality associated with a weekend emergency admission is due to increased illness severity and altered case-mix. Acute Med 2011;10:182-7.

18. Leibowitz R, Day S, Dunt D. A systematic review of the effect of different models of after-hours primary medical care services on clinical outcome, medical workload, and patient and GP satisfaction. Fam Pract 2003;20:311-17.

19. Walsh B, Roberts HC, Nicholls PG. Features and outcomes of unplanned hospital admissions of older people due to ill-defined (R-coded) conditions: retrospective analysis of hospital admissions data in England. BMC Geriatr 2011;11:62. 